\title{
Influência do Uso do Solo no Transporte de Cargas Anuais de Poluentes em Uma Bacia Agrícola
}

\author{
Evelyn Zucco*, Adilson Pinheiro*, Petrick Anderson Soares* \\ evelynzucco@gmail.com; pinheiro@furb.br; petrickps@gmail.com
}

Recebido: 01/05/11 - revisado: 08/07/12 - aceito: 07/11/13

\begin{abstract}
RESUMO
A qualidade da água pode ser afetada por fatores físicos, climáticos, antrópicos e pelo uso e ocupação do solo na bacia hidrográfica. Neste trabalho visa-se avaliar, a influência do uso e ocupação do solo no transporte de cargas anuais de poluentes em uma bacia hidrográfica. O estudo é aplicado na bacia do ribeirão Concórdia, localizada em Lontras - Santa Catarina, que apresenta essencialmente uso agrícola. Foram utilizados dados de qualidade de água, obtidos com coletas mensais, em seis pontos distribuidos espacialmente, ao longo do rio principal e em seus afluentes. As cargas poluentes foram quantificadas a partir de vazões simuladas por modelo hidrológico conceitual. A análise de uso e ocupação do solo na bacia foi proveniente de levantamento realizado em 2008. Os usos e ocupação do solo foram analisados para uma faixa em torno dos cursos de água, considerada como zona ripária e nas bacias contribuintes as seções de controle. Foram efetuadas análises de correlação entre os usos e ocupação do solo e as cargas de poluentes. A condição natural, representada pelo percentual de uso do solo "mata nativa", apresentou influência na redução das cargas de poluentes. Os usos do solo classificados como "pastagem", "floresta plantada" e "atividades agrícolas" apresentaram correlação com o incremento de cargas poluentes no curso de água da bacia. Os usos do solo na zona ripária apresentaram correlação com a qualidade das águas similares àqueles da bacia do ribeirão Concórdia.
\end{abstract}

Palavras- chave: gestão de bacias, qualidade da água, poluição difusa.

\section{INTRODUÇÃO}

As relações entre a agricultura e a qualidade da água são objeto de discussão em diversos estudos (KYLMMAR et al., 2006; LI et al., 2008; KANG et al., 2010). A qualidade da água tem sido associada ao uso e ocupação do solo: estudos têm demonstrado suas relações com as variáveis físico-químicas, tais como nutrientes (QUILBÉ et al., 2006; KYLMMAR et $a l$. , 2006) e sedimentos (AHEARN et al., 2005). A perda de nutrientes pelo escoamento da água e a lixiviação de solos agrícolas têm sido destacadas como duas das principais causas da má qualidade da água nos Estados Unidos (ELRASHIDI et al., 2005).

Em bacias agrícolas, o escoamento é responsável por transporte de nutrientes e sedimentos para a rede de drenagem. Anbumozhi et al. (2005) enfatizam que a qualidade de um corpo de água varia de uma bacia hidrográfica para outra, sendo influenciado pelo uso e ocupação do solo. Miranda e Duarte

*Fundação Universidade Regional de Blumenau/FURB
(2002) argumentam que o excesso de nitrato e pesticidas têm se tornado um grande problema ambiental, visto que as áreas agrícolas possuem diferentes graus de exploração e apresentam potencial de degradação do lençol freático.

As zonas ripárias situadas junto aos corpos de água podem reduzir consideravelmente o transporte de nutrientes e de sedimentos para as águas superficiais e subterrâneas através dos processos de filtração, adsorção, absorção, deposição e desnitrificação (LI et al., 2009). CORRELL (1996), entre outros autores, descrevem os mecanismos gerais pelos quais a vegetação ciliar pode reter, transformar e retirar os sedimentos, o nitrato e o fósforo em solução e adsorvido em partículas em suspensão. Segundo Kamppa e Jauhiainen (2010), as áreas ciliares são uma forma de minimizar o transporte de fósforo pelo escoamento superficial e, assim, diminuir a eutrofização. O desenvolvimento e a gestão de áreas ciliares são considerados opção viável para o controle da poluição agrícola difusa, sendo um reflexo da saúde global da bacia hidrográfica, trazendo muitos benefícios (ANBUMOZHI et al.,2005).

Outros estudos ressaltam a importância das zonas ripárias para a qualidade da água (LI et al., 
2009; YAMADA et al., 2007; ANBUMOZHI et al., 2005). Enquanto Silva e Williams (2001) consideraram o uso e a cobertura do solo em nível de bacia hidrográfica como melhor indicador da qualidade da água do que a zona ripária. Algumas incertezas permanecem, em parte, porque cada bacia hidrográfica tem uma combinação única de características que influenciam a qualidade da água, e em parte porque as investigações aprofundadas em escala de bacia hidrográfica são extremamente dispendiosas e consomem muitos recursos financeiros (Silva e Williams, 2001).

A avaliação das cargas de constituintes na dinâmica da água também é necessária para a gestão da qualidade da mesma, pois auxiliam na compreensão da dinâmica dos nutrientes e nos processos de mobilidade da bacia, além de contribuir na avaliação dos recursos hídricos (LITTLEWOOD e MARSH, 2005).

Neste sentido, este trabalho visa avaliar a influência do uso e ocupação do solo no transporte de cargas anuais de potenciais poluentes na bacia do ribeirão Concórdia. A bacia hidrográfica está localizada no município de Lontras - SC, com uma área de drenagem de $30,74 \mathrm{~km}^{2}$, ocupada por pequenos e médios produtores rurais. Ela foi monitorada em seis seções fluviométricas. Nas áreas contribuintes e nas zonas ripárias foram realizadas classificações do uso e ocupação do solo.

\section{METODOLOGIA}

\section{Área de Estudo}

A bacia do ribeirão Concórdia está localizada no município de Lontras, no estado de Santa Catarina. O ribeirão Concórdia é afluente do rio Lontras e este é afluente do rio Itajaí-açu, situados na bacia do Itajaí. A bacia possui uma área de drenagem de $30,74 \mathrm{~km}^{2}$.Os principais solos que caracterizam a região da bacia são Gleissolo, Cambissolo e Argissolo. A vegetação original da área pertence à Floresta Ombrófila Densa.

Os principais usos do solo estão destinados à mata nativa $(47,61 \%)$, pastagem $(20,35 \%)$ e plantio de milho $(9,29 \%)$. Em termos de população, no levantamento efetuado pela EPAGRI (2005), foi identificado a presença de 600 habitantes, os quais criam, em sistema extensivo, aves (31350 aves), suínos (2520 cabeças), bovinos (9000 cabeças), eqüinos (700 cabeças) e ovinos (220 cabeças). O levantamento não apresenta a distribuição espacial destes animais.
Para a análise da classificação do uso do solo foram utilizados dados referentes ao levantamento realizado por Pinheiro et al. (2008). Foram utilizadas imagens obtidas com o satélite SPOT, do dia 16/01/2006, com resolução espacial de $10 \mathrm{~m}$, em quatro bandas espectrais (verde, vermelho, infravermelho próximo e infravermelho médio) e $2,5 \mathrm{~m}$ no modo pancromático. A classificação da imagem foi supervisionada, ou seja, os resultados obtidos foram comparados com observações realizadas em campo. Foram classificados os usos do solo em eucalipto, pinus, mata nativa, fumo, milho, pastagem e outras atividades agrícolas (hortaliças entre outros) e foram estabelecidas faixas com larguras de 20, 30, 50,100 e $200 \mathrm{~m}$ em torno dos cursos de água.

\section{Aquisição dos dados}

A avaliação da qualidade da água foi realizada por meio de dados de monitoramento realizado pela EPAGRI - Empresa de Pesquisa Agropecuária e Extensão Rural de Santa Catarina. As coletas de água foram realizadas em seis seções fluviométricas, distribuídas ao longo da bacia, conforme Figura 1. Estas coletas ocorreram com frequência mensal.

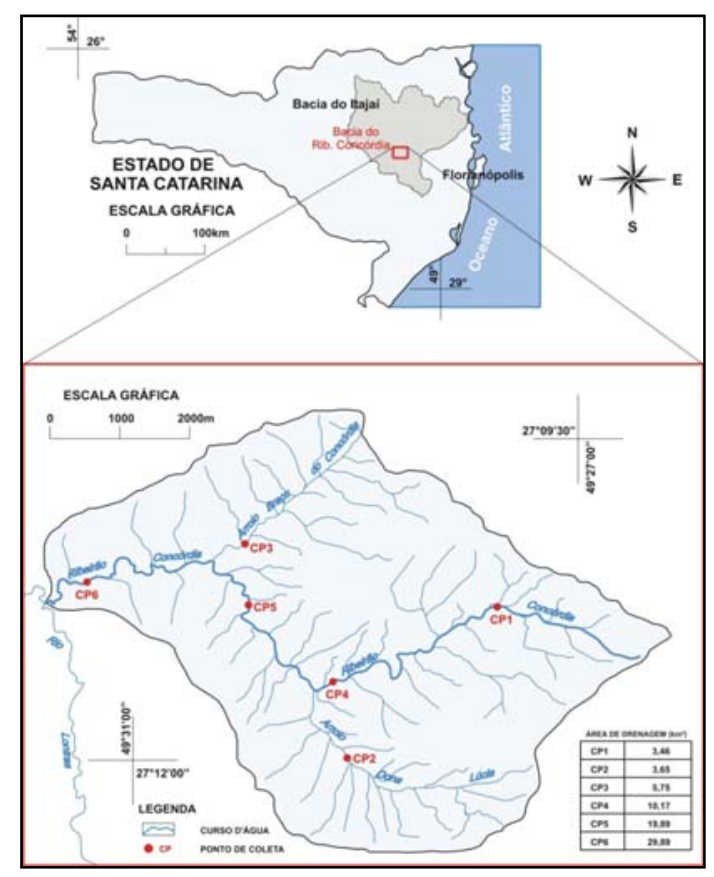

Figura 1 - Área de drenagem e seções de monitoramento de qualidade de água na bacia do ribeirão Concórdia. 
O período de monitoramento foi de 2004 a 2008. As áreas de drenagem das seções de coletas de água variam de 3,46 a 29,89 $\mathrm{Km}^{2}$. Para cada amostra de água foram analisados os seguintes parâmetros (APHA, 1995): fósforo total; demanda química de oxigênio; ortofosfato; amônia; nitrito; nitrato; potássio; ferro total; coliformes totais e coliformes termotolerantes. As análises microbiológicas foram realizadas através do método de cartelas com reativo "Colilert". As análises foram realizadas no laboratório da EPAGRI, na estação experimental de Itajaí.

O monitoramento realizado pela EPAGRI contém apenas as concentrações dos parâmetros de qualidade das águas. Não foram realizadas medições de vazões, necessárias para determinação das cargas transportadas. Para preencher esta lacuna, foi utilizado o modelo hidrológico WIN_IPH2 (BRAVO et $a l .$, 2006). Foram geradas as séries de vazões diárias a partir do conhecimento da série de precipitação.

O modelo WIN_IPH2 é composto por algoritmos de perdas de evaporação e interceptação, separação do escoamento e propagação dos escoamentos superficiais e subterrâneos. A bacia possui uma seção fluviométrica de monitoramento de vazão. Os dados desta seção foram utilizados na calibração do modelo WIN_IPH2. A calibração do modelo foi realizada para o período de janeiro de 2006 a dezembro de 2008. Durante esse período, uma estação pluviométrica e uma fluviométrica com $d a$ tallogers situadas próximas ao exutório da bacia (ponto CP6 indicado na Figura 1) estavam em operação. Os parâmetros calibrados são apresentados na Tabela 1, e o método de calibração foi o manual.

Tabela 1 - Parâmetros calibrados no modelo WIN_IPH2.

\begin{tabular}{|c|c|}
\hline $\begin{array}{l}\text { Parâme- } \\
\text { tros }\end{array}$ & Descrição \\
\hline $\mathbf{R}_{\max }$ & $\begin{array}{l}\text { Capacidade máxima do reservatório de } \\
\text { interceptação }\end{array}$ \\
\hline $\mathbf{I}_{\mathrm{o}}$ & $\begin{array}{l}\text { Capacidade de infiltração do solo quando } \\
\text { o solo está na capacidade de campo }\end{array}$ \\
\hline $\mathbf{I}_{\mathrm{b}}$ & $\begin{array}{l}\text { Capacidade de infiltração quando o solo } \\
\text { está saturado }\end{array}$ \\
\hline $\mathbf{H}$ & $\begin{array}{l}\text { Parâmetro empírico relacionado ao tipo de } \\
\text { solo }\end{array}$ \\
\hline $\mathbf{K}_{\mathrm{s}}$ & $\begin{array}{l}\text { Tempo médio de esvaziamento do reserva- } \\
\text { tório superficial }\end{array}$ \\
\hline $\mathbf{K}_{\text {sub }}$ & $\begin{array}{l}\text { Tempo médio de esvaziamento do reserva- } \\
\text { tório subterrâneo }\end{array}$ \\
\hline$\alpha$ & $\begin{array}{l}\text { Parâmetro que corrige parcela do escoa- } \\
\text { mento superficial }\end{array}$ \\
\hline
\end{tabular}

Foi gerada uma série de vazão utilizando a série histórica de precipitação diária coletada na estação de Rio do Sul (código 02749039). Para cada seção de amostragem de água foi gerada uma série de vazões médias diárias. A geração de vazões foi realizada para o período do monitoramento dos parâmetros de qualidade das águas, compreendido entre 2004 e 2008.

\section{Determinação da carga anual}

A estimativa das cargas anuais de poluentes na bacia é necessária para se obter uma boa avaliação da poluição da água(QUILBÉ et al., 2006).

As cargas transportadas em cada seção foram calculadas pelo produto da vazão simulada e da concentração na data de coleta. A carga anual foi obtida pela equação apresentada por Moatar e Meybeck (2005), expressa por:

$\mathrm{F}=\mathrm{K} \frac{\sum_{\mathrm{i}=1}^{\mathrm{n}} \mathrm{CiQi}}{\sum_{\mathrm{i}=1}^{\mathrm{n}} \mathrm{Qi}} \overline{\mathrm{Q}}$

onde $\mathrm{F}$ é a carga poluente $\left(\mathrm{Mg} \mathrm{ano}^{-1}\right)$; $\mathrm{K}$ é um fator de conversão de unidades de tempo, $\mathrm{C}_{\mathrm{i}}$ é a concentração instantânea $\left(\mathrm{mg} \mathrm{L}^{-1}\right) ; Q_{\mathrm{i}}$ é a vazão instantânea $\left(\mathrm{m}^{3} \mathrm{~s}^{-1}\right), \bar{Q}$ é a vazão média do período em análise $\left(\mathrm{m}^{3} \mathrm{~s}^{-1}\right)$ e n é o número de passos temporais.

\section{Análise estatística}

As relações entre as variáveis de qualidade da água com o uso do solo na bacia e na zona ripária foram determinadas utilizando o coeficiente de correlação de Pearson.

\section{RESULTADOS E DISCUSSÃO}

\section{Geração de séries de vazões}

Na simulação do modelo WIN_IPH2 foi adotado o passo de tempo diário, visto que as séries temporais disponíveis eram diárias. A calibração do modelo às séries de dados do período selecionado apresentou coeficiente de Nash-Sutcliffe de 0,62 (período entre 01/01/2006 a31/12/2008). Na etapa de validação do modelo foi obtido coeficiente de 0,40 (ano de 2009). Na Figura 2 são apresentados hidrogramas observados e simulados nos períodos de calibração e de validação do modelo. Ressalta-se que a calibração e a validação do modelo foram efetuadas para a maior área de drenagem da bacia. A geração de séries temporais nas seções fluviométricas de montante, com menores áreas de drena- 
gem pode induzir imprecisões, devido à mudança de escala, conforme foi mostrado por Oliveira et al. (2013).

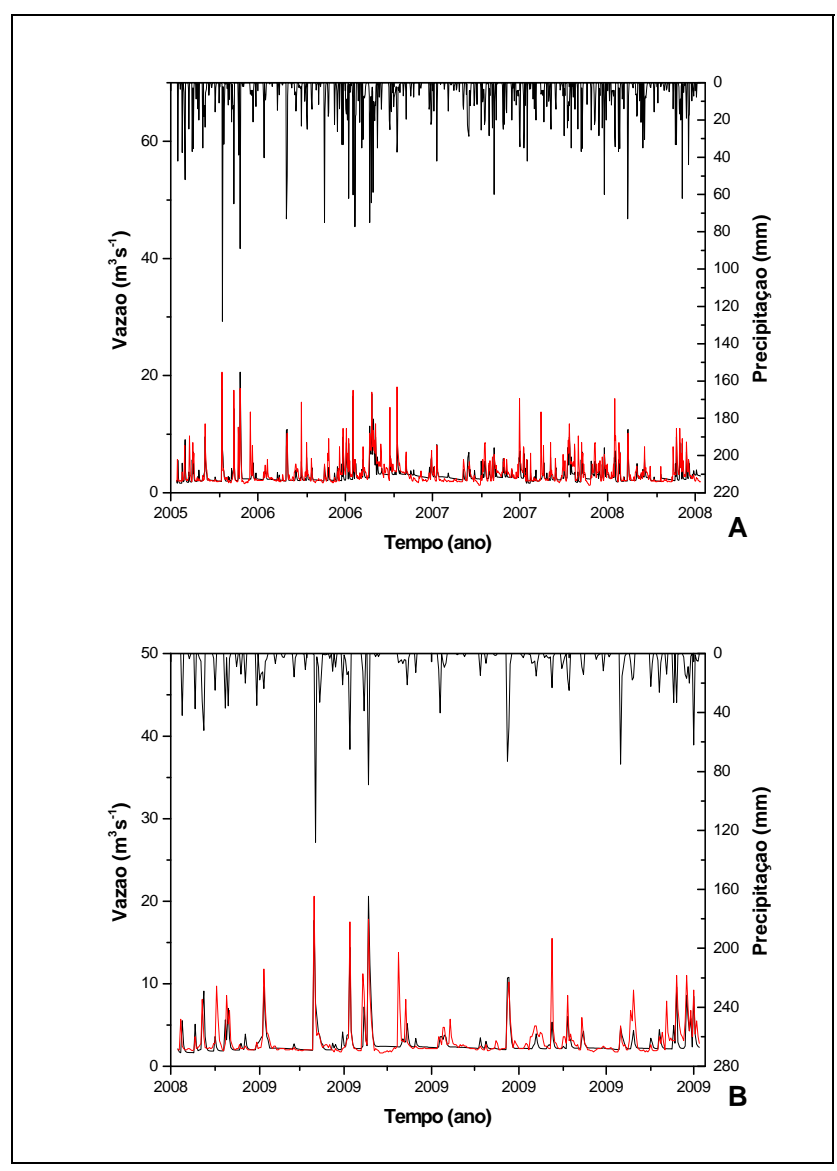

Figura 2 - Hidrogramas observados e simulados na calibração (A) e validação (B). A linha vermelha representa a vazão observada, enquanto que a linha preta representa a vazão calculada.

\section{Uso do solo na bacia e na zona ripária}

Na Figura 3 é apresentada a distribuição do uso do solo na zona ripária, nas distâncias de 0 a 200m. Nota-se que o percentual de uso e ocupação classificado como mata nativa corresponde a cerca de $50 \%$ da área de drenagem das seções de amostragem, sendo o menor percentual $(48,46 \%)$ observado para a faixa de 0 a $100 \mathrm{~m}$. O percentual de uso e ocupação da pastagem reduz com o aumentoda largura da faixa em torno dos cursos de água. Situação contrária acontece com o uso do solo agrícola, como o milho e o fumo. O uso de solo classificado como "milho" apresentou percentuais de 6 e $9 \%$ na faixa de 0 a $20 \mathrm{~m}$ e 0 a $200 \mathrm{~m}$, respectivamente, en- quanto que o fumo, apesar de apresentar comportamento similar, resultou em índices percentuais menores, de 0,14 a $0,52 \%$, na faixa de 0 a $20 \mathrm{~m}$ e 0 a $200 \mathrm{~m}$, respectivamente.

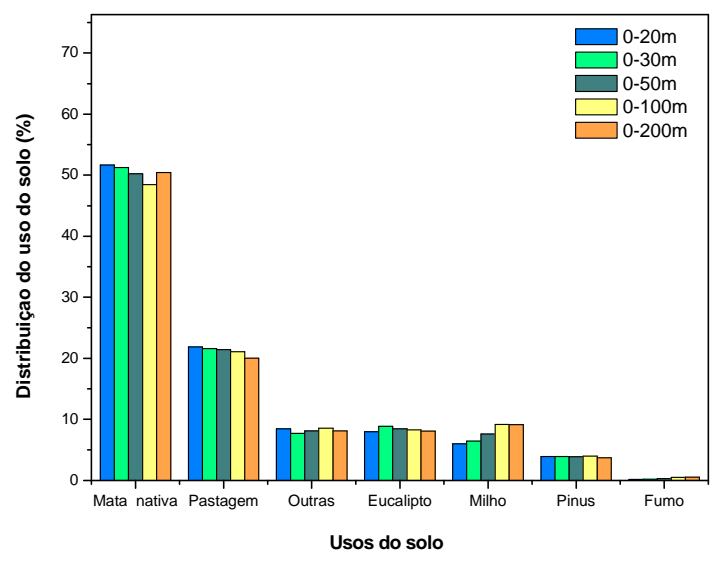

Figura 3 - Distribuição do uso e ocupação do solo na zona ripária (imagem SPOT, do dia 16/01/2006)

A Figura 4 apresenta a distribuição do uso e ocupação do solo nas seções de monitoramento na bacia do ribeirão Concórdia. Os valores apresentados correspondem aos usos e ocupação nas áreas incrementais, entre as seções de monitoramento dos parâmetros de qualidade das águas.

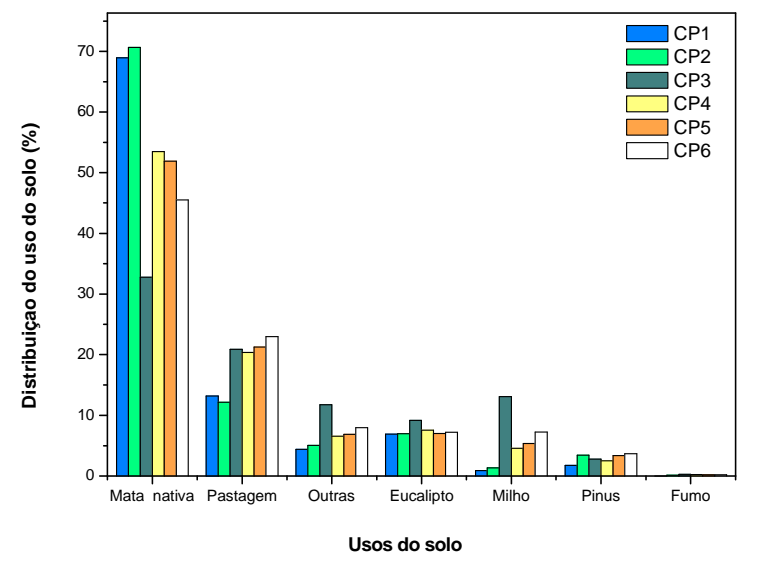

Figura 4 - Distribuição do uso do solo na bacia do ribeirão Concórdia (imagem SPOT, do dia 16/01/2006).

A análise mostra que a vegetação nativa é o tipo de cobertura do solo dominante, como também foi observado nas faixas da zona ripária, representando $45 \%$ do solo na bacia. Observa-se que a seção CP3 apresenta os maiores percentuais de área agrícola, chegando a $13 \%$ para o uso de solo "milho". A 
pastagem ocupa cerca de $13 \%$ da paisagem da bacia de captação tanto da seção CP1 quanto da seção CP2, sendo que no ponto CP6, localizado na foz da bacia, o uso "milho" atinge percentuais de $23 \%$.

O percentual uso do solo agrícola aumenta para as seções de monitoramento com maior área de drenagem.A mata nativa, apesar de ser dominante na paisagem da bacia,apresenta uma evolução contrária. Com o afastamento das seções de monitoramento das nascentes, ocorre uma diminuição da mata nativa presente.

\section{Carga anual na bacia}

Os resultados são apresentados em termos de carga média em cada seção amostrada. A carga média anual é apresentada na Tabela 2, disposta em ordem crescente de área de contribuição. Os maiores valores de carga encontrados foram correspondentes às seções CP3 e CP6. A seção CP3 está localizada no ribeirão Braço do Concórdia, afluente do rio principal, enquanto que CP6 está localizado próximo ao exutório da bacia. Os menores valores encontrados correspondem a CP1, localizado no arroio Dona Lúcia, sendo o ponto mais próximo da nascente.

Os valores, embora demonstrem uma contribuição de carga uniforme na bacia, apresentam evolução da nascente para a foz. Tal comportamento também foi encontrado por Anbumozhi et al. (2005). Eles encontraram valores crescentes de nitrato a partir da nascente da bacia estudada. Os autores justificaram os maiores valores encontrados a jusante devido à contribuição de fertilizantes químicos aplicados na área agrícola. $\mathrm{Na}$ bacia do ribeirão Concórdia, a atividade agrícola é desenvolvida em pequenas e médias propriedades, cujos produtores sobrevivem da agricultura familiar e não fazem uso de práticas conservacionistas.

As cargas de DQO e de coliformes apresentaram valores elevados desde a seção CP1 (Tabela 2). Este fato pode ser atribuído às atividades de criação de animais na bacia e ao lançamento de águas residuárias domésticas. Estes resultados estão de acordo com Merten e Minella (2002), os quais relatam que as atividades de pecuária representam grande risco à qualidade de corpos hídricos, quando nestas não são adotadas práticas de manejo conservacionistas, elevando os valores de $\mathrm{DBO}$ e coliformes termotolerantes. Pinto et al. (2009) relatam em sua pesquisa um aumento dos valores de coliformes, devido às áreas de pastagem.

$\mathrm{Na}$ bacia do ribeirão Concórdia, as águas residuárias são tratadas em sistemas individuais simpli- ficados. Os demais resíduos animaisnão recebem tratamentos específicos. No entanto, ressalta-se que estes lançamentos ocorrem de forma distribuída ao longo de toda a bacia. Deste modo, pode-se considerar que as contribuições aos cursos de água são uniformes.

A carga média anual de fósforo total na seção CP6 foi de 0,64 kg ha-1 ano $^{-1}$. Cargas com valores mais elevados foram encontrados por Quilbé et al. (2006). Os autores estimaram a carga média de fósforo total, em uma bacia de $718 \mathrm{~km}^{2}$, com $32 \%$ de agricultura, de $1,09 \mathrm{~kg} \mathrm{ha} \mathrm{ano}^{-1}$. Kyllmar et al. (2006) encontraram valores de cargas anuais de fósforo total de 0,1 a $0,9 \mathrm{~kg} \mathrm{ha}^{-1} \mathrm{ano}^{-1}$, semelhantes aos encontrados neste trabalho.

As cargas de amônia foram elevadas em todas as seções monitoradas, tendo variado entre 9,13 e 18,28 kg ha ${ }^{-1}$ ano $^{-1}$. Segundo Kato et. al. (2009) a criação de animais, resulta em aumentos de nitrogênio e fósforo nos corpos de água.Na bacia do ribeirão Concórdia, Lubitz (2009) estimou que a carga de nitrogênio, contida nos resíduos orgânicos humanos e animais, é da ordem de $852 \mathrm{~kg} \mathrm{~d}^{-1}$. Ressalta-se, ainda que as contribuições são uniformemente distribuídas ao longo da bacia. Em termos de distribuição temporal, pode-se considerar que a sequência de cultivos sucessivos, a época de aplicação de adubo, o calendário de plantio, entre outros, são fatores antrópicos que podem influenciar a carga de nitrogênio em cursos de água, conforme foi constatado por Kyllmar et al. (2006).

A vegetação ripária exerce um papel fundamental na eliminação do nitrogênio através da desnitrificação. Além disto, a produção de $\mathrm{NO}_{3}^{-}$ dentro do canal pode ocorrer a partir da mineralização da matéria orgânica. Por outro lado, Chaves e Santos (2009), não encontraram aumento do parâmetro amônia, atribuindo isso ao fato de a zona ripária ter se mantido íntegra no período do estudo. Este fato, além do manejo e da gestão da área agrícola, pode contribuir para os valores mais elevados de nitrogênio no decorrer da área de drenagem.

\section{Relação entre a carga anual de poluentes e o uso e ocupação do solo na zona ripária}

Para efeito de análise de correlação entre a carga de poluente e os percentuais de uso e ocupação do solo, foi considerada a faixa ciliar com largura de $30 \mathrm{~m}$. Esta largura de faixa corresponde ao valor estabelecido pela lei federal $\mathrm{n}^{\circ} 4.771 / 1965$, para rios que possuem largura inferior a $10 \mathrm{~m}$. Os dados utilizados para a análise na zona ripária são referentes ao estudo realizado por Pinheiro et al. 
Tabela 2 - Carga específica média anual $\left(\mathrm{Kg} \mathrm{ha}^{-1} \mathrm{ano}^{-1}\right)$ nas seções de monitoramento na bacia do ribeirão Concórdia, período de 2004-2008.

\begin{tabular}{|c|c|c|c|c|c|c|c|c|c|c|}
\hline \multirow{2}{*}{ Seção } & \multirow{2}{*}{ Fósforo } & \multirow{2}{*}{ Ortofosfato } & \multirow{2}{*}{ Amônia } & \multirow{2}{*}{ Nitrito } & \multirow{2}{*}{ Nitrato } & \multirow{2}{*}{ DQO } & \multirow{2}{*}{$\begin{array}{l}\text { Ferro } \\
\text { Total }\end{array}$} & \multirow{2}{*}{ Potássio } & \multicolumn{2}{|c|}{ Coliformes (NMP/ha/ano) } \\
\hline & & & & & & & & & Totais & Termotolerantes \\
\hline CP1 & 0,45 & 0,20 & 9,13 & 0,05 & 1,47 & 79,45 & 1,13 & 7,75 & $1,09 \times 10^{9}$ & $6,45 \times 10^{5}$ \\
\hline CP2 & 0,61 & 0,32 & 11,01 & 0,08 & 2,37 & 85,22 & 2,01 & 12,64 & $8,12 \times 10^{8}$ & $5,34 \times 10^{5}$ \\
\hline CP3 & 0,70 & 0,35 & 12,43 & 0,11 & 3,48 & 140,34 & 3,13 & 14,73 & $2,05 \times 10^{9}$ & $3,88 \times 10^{6}$ \\
\hline $\mathrm{CP} 4$ & 0,69 & 0,34 & 12,23 & 0,11 & 2,68 & 109,43 & 2,28 & 12,98 & $4,39 \times 10^{9}$ & $2,90 \times 10^{6}$ \\
\hline CP5 & 0,81 & 0,44 & 18,09 & 0,12 & 3,20 & 100,75 & 5,54 & 18,66 & $9,88 \times 10^{6}$ & $6,45 \times 10^{5}$ \\
\hline $\mathrm{CP6}$ & 0,64 & 0,30 & 18,28 & 0,10 & 4,14 & 422,75 & 8,70 & 25,13 & $4,92 \times 10^{11}$ & $9,29 \times 10^{7}$ \\
\hline
\end{tabular}

(2008). Para este estudo, adotou-se o uso do solo da floresta plantada como sendo aqueles classificados como plantação de pinus e de eucalipto,eatividades agrícolas inclui os usos do solo milho, fumo e outras atividades.

Nas Figuras 5 e 6 são apresentadas as relações entre as cargas dos poluentes com o percentual de atividade agrícola e de pastagem. Nota-se que o aumento das áreas de plantio de milho e fumo, de outras atividades agrícolas e de pastagem acarreta noacréscimo da carga dos poluentes transportada no sistema fluvial (Figuras 5 e 6 ). Isto ocorre para todos os parâmetros monitorados, e indica uma possível relação entre as cargas poluentes encontradas nos corpos de água com o uso do solo existente na zona ripária. Resultado similar foi obtido com relação a floresta plantada, conforme é apresentado na Figura 7.

No entanto, nota-se que o uso e ocupação do solo "mata nativa" apresenta relação inversamente proporcional com a carga encontrada nos corpos de água, conforme é apresentado na Figura 8. Isso pode representar que com a maior presença de vegetação nativa na zona ripária, a carga é reduzida para os cursos de água, auxiliando assim na redução de poluentes na rede de drenagem.

Li et al. (2009) descrevem que, em geral, os parâmetros físico-químicos em corpos de água são controlados pela cobertura florestal e pelas terras com vegetação (incluindo mata e arbustivas). Pinto et al. (2009), atribuem à presença de mata nativa em áreas ripárias, o melhor nível da qualidade da água em alguns trechos da bacia estudada. Anbumozhi et al. (2005) ressaltam o impacto positivo das zonas ripárias na redução de nutrientes da agricultura para as águas superficiais. Os autores ainda concluem que as zonas ripárias são eficazes na redução da poluição das águas provenientes de campos agrícolas.

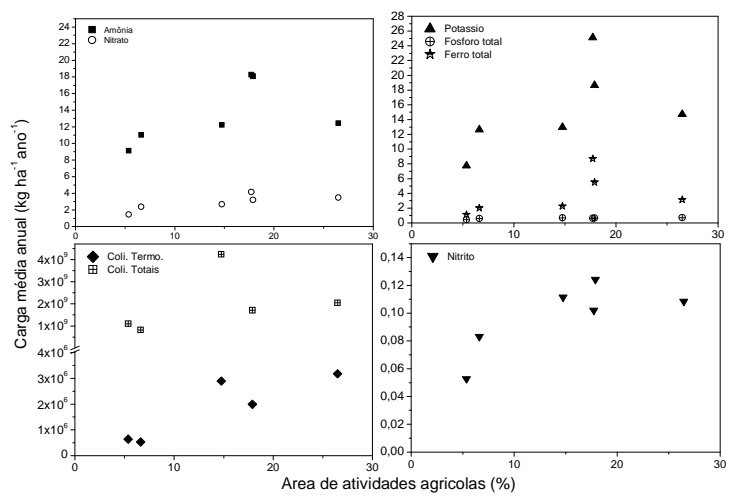

Figura 5 - Relação entre o uso do solo "atividades agrícolas" na zona ripária e a carga média dos poluentes selecionados nas seções de monitoramento, no período de 2004-2008.

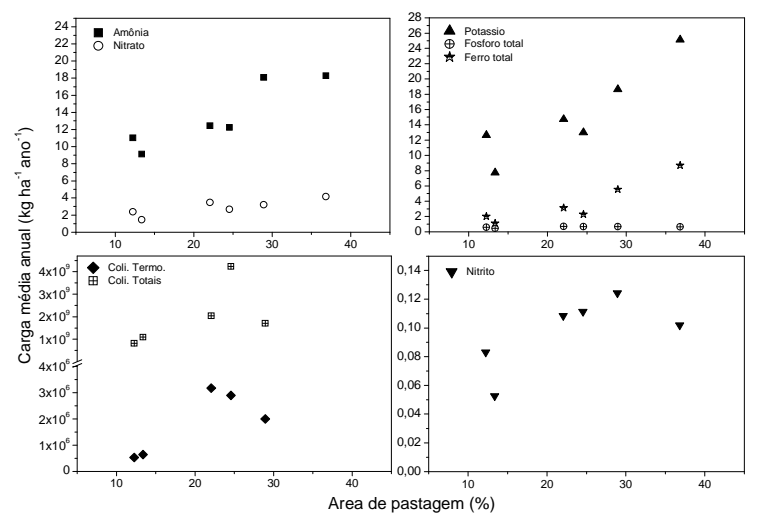

Figura 6 - Relação entre o uso do solo "pastagem" na zona ripária e a carga média dos poluentes selecionados nas seções de monitoramento, no período de 2004-2008. 
Tabela 3 - Coeficiente de correlação de Pearson entre os parâmetros de qualidade de água e o uso e ocupação do solo na bacia e na faixa ciliar (ZR) do ribeirão Concórdia, no período de 2004-2008.

\begin{tabular}{|c|c|c|c|c|c|c|c|c|c|c|c|c|}
\hline & \multicolumn{2}{|c|}{$\begin{array}{c}\text { Floresta } \\
\text { Plantada } \\
\end{array}$} & \multicolumn{2}{|c|}{ Mata Nativa } & \multicolumn{2}{|c|}{$\begin{array}{c}\text { Outras Atividades } \\
\text { Agrícolas } \\
\end{array}$} & \multicolumn{2}{|c|}{ Pastagem } & \multicolumn{2}{|c|}{ Fumo } & \multicolumn{2}{|c|}{ Milho } \\
\hline & Bacia & $\mathrm{ZR}$ & Bacia & ZR & Bacia & ZR & Bacia & ZR & Bacia & ZR & Bacia & ZR \\
\hline $\begin{array}{l}\text { Fósforo } \\
\text { Total }\end{array}$ & 0,20 & 0,33 & 0,43 & 0,52 & 0,44 & 0,60 & 0,26 & 0,29 & 0,40 & 0,61 & 0,51 & 0,59 \\
\hline Orto-fosfato & 0,24 & 0,05 & 0,37 & 0,26 & 0,38 & 0,28 & 0,36 & 0,18 & 0,39 & 0,18 & 0,27 & 0,33 \\
\hline Amônia & 0,51 & 0,07 & 0,64 & 0,58 & 0,50 & 0,22 & 0,96 & 0,83 & 0,32 & $>0,01$ & 0,25 & 0,30 \\
\hline Nitrito & 0,47 & 0,25 & 0,61 & 0,61 & 0,61 & 0,53 & 0,51 & 0,47 & 0,31 & 0,34 & 0,48 & 0,59 \\
\hline Nitrato & 0,35 & 0,40 & 0,72 & 0,83 & 0,59 & 0,61 & 0,68 & 0,74 & 0,81 & 0,09 & 0,61 & 0,64 \\
\hline DQO & 0,10 & 0,11 & 0,28 & 0,38 & 0,12 & 0,10 & 0,38 & 0,60 & 0,58 & $>0,01$ & 0,11 & 0,12 \\
\hline Ferro Total & 0,35 & 0,09 & 0,53 & 0,55 & 0,36 & 0,18 & 0,83 & 0,84 & 0,47 & 0,02 & 0,22 & 0,24 \\
\hline Potássio & 0,30 & 0,12 & 0,55 & 0,61 & 0,38 & 0,25 & 0,81 & 0,83 & 0,54 & $>0,01$ & 0,28 & 0,31 \\
\hline Coli. Totais & 0,06 & 0,04 & 0,14 & 0,25 & 0,05 & 0,03 & 0,32 & 0,52 & 0,42 & 0,04 & 0,04 & 0,04 \\
\hline Coli. Term. & 0,06 & 0,05 & 0,15 & 0,27 & 0,06 & 0,04 & 0,33 & 0,54 & 0,45 & 0,03 & 0,05 & 0,05 \\
\hline
\end{tabular}

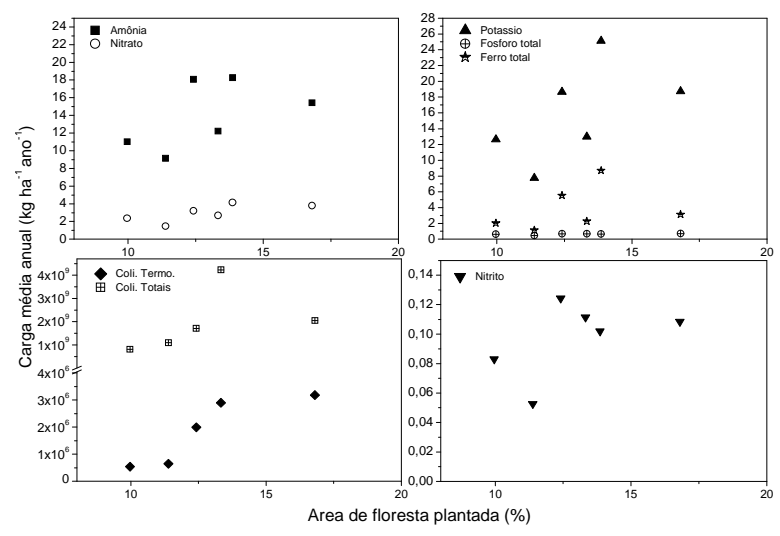

Figura 7 - Relação entre o uso do solo "floresta plantada" na zona ripária e a carga média dos poluentesselecionados nas seções de monitoramento,no período de 2004-2008.

Visando avaliar o grau de relação entre o uso e ocupação do solo e as cargas de poluentes nas seções monitoradas foi calculado o coeficiente de correlação de Pearson. Neste caso, a carga é aquela produzida na área entre as seções monitoradas.

A correlação de Pearson foi realizada para duas condições. A primeira considera o uso e ocupação do solo na bacia incremental e a segunda considera o uso e ocupação no solo na faixa ciliar com largura de $30 \mathrm{~m}$. Na Tabela 3 são apresentados os coeficientes de correlação obtidos entre os percentuais de uso ocupação do solo nas duas condições e a carga média na seção monitorada.

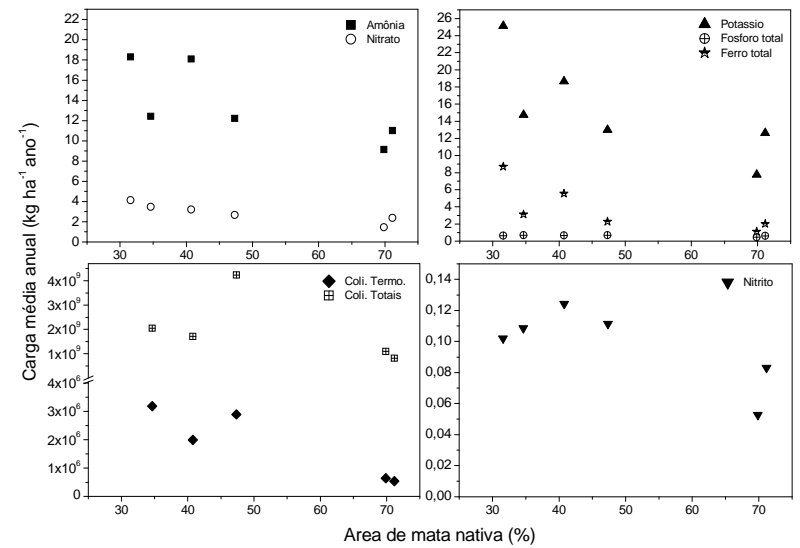

Figura 8 - Relação entre o uso do solo "mata nativa" na zona ripária e a carga média dos poluentes selecionados nas seções de monitoramento, no período de 2004-2008.

Nota-se que as correlações entre os percentuais de uso e ocupação do solo e as cargas de coliformes totais e termotolerantes são fracas, apresentando coeficientes inferiores a 0,54. O maior valor ocorreu na correlação entre o uso do solo por pastagens da faixa ciliar e coliformes termotolerantes. Para coliformes totais o coeficiente de correlação foi de 0,52. Nos dois casos, os resultados mostram que a pastagem na faixa ciliar de $30 \mathrm{~m}$ pode contribuir com o aumento da carga de coliformes. Isto pode ser devido aos dejetos liberados pelos animais nas pastagens ou diretamente aos cursos de água. 
O uso e ocupação do solo por pastagem e de mata nativa apresentaram coeficientes de correlações elevados, tanto na bacia quanto na faixa ciliar com as cargas dos compostos de nitrogênio (amônia, nitrito e nitrato), ferro total e potássio. Isto poderia indicar que estes usos constituem importantes fontes destas espécies químicas. Igualmente os dejetos liberados pelos animais nas pastagens e a decomposição da serapilheira na mata nativa seriam as fontes de compostos de nitrogênio, ferro e potássio.

Os coeficientes de correlação das cargas de nitrito e de nitratos são superiores a 0,50 quando analisados em relação os usos mata nativa, outras atividades agrícolas, pastagem e milho. Deste modo, os fertilizantes utilizados na agricultura seriam fontes destes compostos de nitrogênio nos cursos de água.Pinheiro e Deschamps (2008) apresentaram correlações entre o uso do solo e o transporte de ortofosfato e nitratos em uma bacia agrícola, no qual existem aportes pontuais e difusos. Verificaram que os coeficientes de correlações são elevados. Li $e t$ al. (2008) encontraram correlação significativa entre a carga de nitrogênio com a cobertura da vegetação da bacia estudada.

Coeficientes de correlação fracos foram obtidos com as cargas de ortofosfatos e de DQO para todos os usos e ocupação do solo considerados. Os valores mais elevados da correlação da DQO foram obtidos com o uso por pastagem na faixa ciliar e por fumo. No primeiro caso poderia ser explicado pelos dejetos amimais. Para o fumo, a explicação pode ser o uso de fertilização orgânica. Segundo Troian (2009) para a preparação da lavoura, no plantio de fumo, é utilizada, além de produtos químicos, a adubação orgânica.É importante notar que os coeficientes de correlação, em geral, foram da mesma ordem de grandeza, entre os percentuais de uso e ocupação do solo na bacia e na faixa ciliar. Assim, para o caso da bacia do ribeirão Concórdia, onde se têm pequenas e médias propriedades e com agricultura familiar, não foi possível identificar as vantagens largamente descritas das faixas ciliares sobre as cargas de poluentes transportados pelos cursos de água.

Muitas pesquisas (LIMA, 1989; MIRANDA e DUARTE, 2002;LEE et al., 2003) têm se voltado para a importância da zona ripária na qualidade da água, devido aos seus processos atuantes. Os estudos relatam as transformações bioquímicas de nitrogênio, responsáveis pela absorção de nitrato e amônia, ou até mesmo a redução de fósforo em áreas ciliares. Embora estes estudos demonstrem o potencial de interferência que a zona ripária pode produzir nas cargas poluentes, a análise desenvolvida por muitas pesquisas dificulta a avaliação, pois nem sempre é realizada uma análise comparativa com as cargas da bacia, como foi neste trabalho.

\section{CONCLUSÕES}

Realizou-se o estudo sobre a correlação dos usos do solo na bacia e em zonas ripárias com as cargas poluentes transportadas pelos cursos de água na bacia do ribeirão Concórdia. O uso do solo por pastagem e de mata nativa apresentaram coeficientes de correlação elevados, tanto com os percentuais da bacia quanto da faixa ciliar, com as cargas de amônia, nitrito, nitrato, ferro total e potássio. $\mathrm{Na}$ pastagem, os dejetos liberados pelos animais podem ser os principais contribuintes dessesconstituintes químicos. Devido as esses resíduos - dejetos -,a presença de pastagem também contribui com os coliformes totais e termotolerantes presentes nos cursos de água. A mata nativa também apresentou coeficientes de correlação elevados com os compostos de nitrogênio, ferro total e potássio, podendo indicar que estes usos constituem importantes fontes destas substâncias químicas.

É importante ressaltar que na bacia do ribeirão Concórdia, os coeficientes de correlação entre os percentuais de uso e ocupação do solo e as cargas de poluentes analisados, foram similares na bacia e na faixa ciliar de $30 \mathrm{~m}$.Isto pode ser devido ao percentual de preservação na bacia e na zona ripária. Por outro lado, isto dificulta uma discriminação dos impactos que podem ou não ser gerados pelo uso do solo em zonas ripárias.

\section{AGRADECIMENTOS}

Agradecemos ao MCT/FINEP/CT-HidroCNPq, edital 04/2005 Bacias Representativas, convênio 3490/05 e MCT/FINEP/AÇÃO TRANSVERSAL - Previsão de Clima e Tempo 04/2008, convênio 1406/08, pelo financiamento da pesquisa, a CAPES pelas bolsas de mestrado, a EPAGRI pelo fornecimento dos dados de qualidade das águas e aos revisores pelas preciosas contribuições na redação do artigo.

\section{REFERÊNCIAS}

AHEARN, D.S., SHEIBLEY, R.S., DAHLGREn, R.A., ANDERSON, M., JOHNSON, J., TATE, K.W. Land use and land cover influence on water quality in the last free-flowing 
river draining the western Sierra Nevada, California. Journal of Hydrology, v.313, p.234-247,2005.

ANBUMOZHI, V., RADHAKRISHNAN, J.; YAMAJI, E. Impact of riparian buffer zones on water quality and associated management considerations. Ecological Engineering, p.517-523, 2005.

APHA (1995): APHA. Standard methods for the examination of water and wastewater. American Public Health Association, New York, 1995.

BRAVO, J. M.; ALLASIA,D.; TASSI,R.; MELLER,A.; COLLISCHONN,W.; TUCCI, C.E.M. (2006). Manual de usuário do modelo hidrológico WIN_IPH2. 63p.

CHAVES, H. M. L. e SANTOS, L. B. dos. Ocupação do solo, fragmentação da paisagem e qualidade da água em uma pequena bacia hidrográfica. Revista brasileira de EngenhariaAgrícola e Ambiental, v.13, p. 922-930, 2009.

CORRELL (1996). CORREL, D. L. Buffer zones and water quality protection: general principles.In: Buffer Zones: their processes and potential in water protection, 1996.

ELRASHIDI, M. A.; MAYS, M. D. FARES, A.; SEYBOLD, C. A.; HARDER, J. L.; PEASLEE, S. D. VANNESTE, P. Loss of Nitrate-Nitrogen By Runoff and Leaching for Agricultural Watersheds. Soil Science, v. 170, p. 969-984, 2005.

EPAGRI. Projeto Microbacias2: relatório síntese - monitoramento socioeconômico. Dez. 2005. Disponível em: $<$ http://www.microbacias.sc.gov.br>. Acesso em 26 de julho de 2012.

KAMPPA e JAUHIAINEN (2000). Na verdade 0 ano é 2010,no artigo é este 0 ano também. Kamppa-Uusi, J. ; Jauhiainen, L. Long- term monitoring of buffer zone efficiency under different cultivation techniques in boreal conditions. Agriculture, Ecosystems and Environemnt, v. 137, p. 75-85, 2010.

KANG, J.-H.; LEE, S. W.; CHO, K. H.; KI, S. J.; CHA, S. M.; $\mathrm{KIM}, \mathrm{J}$. H. Linking land-use type and stream water quality using spatial data of fecal indicator bacteria and heavy metals in the Yeongsan river basin. Water Research, v.44, p. 41434157,2010 .

KATO, T.; KURODA, H.; NAKASONE, H. Runoff characteristics of nutrients from an agricultural watershed with intensive livestock production. Journal of Hydrology, v.368, p. 79-87, 2009.

KYLLMAR, K., MARTENSSON, K., JOHNSSON, H. Modelbased coefficient method for estimation of $\mathrm{N}$ leaching from agricultural fields applied to small catchments and the effects of leaching reducing measures. Journal of Hydrology, v. 304, p. 343-354, 2006.

LI, S.; GU, S.; LIU, W.; HAN, H.; ZHANG, Q. Water quality in relation to land use and land cover in the upper Han River Basin, China. Catena, v.75, p.216-222, 2008.

LI, S.; GU, S.; TAN, X.; ZHANG, Q. Water quality in the upper Han River basin, China: The impacts of land use/land cover in riparian buffer zone. Journal of Hazardous Materials, v. 165, p. 317-324, 2009.

LIMA (1989): LIMA, W. P. Função hidrológica da mata ciliar. In: Simposio sobre mata ciliar, Fundação Cargill, p. 25-42, 1989.

LUBITZ. E. Avaliação da aplicação do modelo hidrológico SWAT à bacia do ribeirão Concórdia Lontras, SC. 2009. 125 p. Dissertação (Mestrado em Engenharia Ambiental) - Fundação Universidade Regional de Blumenau,.

LITTLEWOOD e MARSH (2005). Littlewood, I. G.; Marsh, T. J. Annual freshwater river mass loads from Great Britain, 19751994: estimation algorithm, database and monitoring network issues. Journal of Hydrology, v. 304, p. 221-237, 2005.

MERTEN, G. H.; MINELLA, J. P. Qualidade da água em bacias hidrográficas rurais: um desafio atual para sobrevivência futura. Agroecologia e Desenvolvimento Rural Sustentável, v. 3, n. 4, out./dez. 2002.

MIRANDA, J. H. de; DUARTE, S. N. Modelo para simulação da dinâmica de nitrato em colunas verticais de solo não saturado. Revista Brasileira de Engenharia Sanitária e Ambiental, v.6, n.2, p. 235-241, 2002.

MOATAR, F.; MEYBECK, M.Compared performances of different algorithms for estimating annual nutrient loads discharged by the eutrophic River Loire. Hydrological Processes, v. 19, p. 429-444, 2005.

OLIVEIRA, G.; PEDROLLO, O. C.; CASTRO, N. M. R.; BRAVO, J. M. Simulações hidrológicas com diferentes proporções de área controlada na bacia hidrográfica. Revista Brasileira de Recursos Hídricos, 2013 (in presse).

PINHEIRO, A.; BERTOLDI, J.; VIBRANS, A. C.; REFOSCO, J. C. Relação entre 0 uso da terra da faixa ciliar e a qualidade das águas em uma bacia agrícola. In: Congresso Interamericano AIDIS, XXXI, 2008, Santiago - Chile, anais eletrônicos, AIDIS, 2008. 1 CD-ROM. 
PINHEIRO, A.; DESCHAMPS, F. C. Transporte de ortofosfato e de nitrato na microbacia do Ribeirão Fortuna, SC. Revista Brasileira de Engenharia Agrícola e Ambiental, v.12, n.3, p.318-325, 2008.

PINTO, D. B. F.; SILVA,A. M. da; MELLO, C. R. de; COELHO, G.. Qualidade da água do ribeirão lavrinha na região alto rio grande - MG, Brasil. Ciência Agrotécnica, v. 33, n. 4, p. 11451152, jul./ago. 2009.

QUILBÉ, R., ROUSSEAU, A. N., DUCHEMIN, M., POULIN, A., GANGBAZO, G., VILLENUEVE, J.P.. Selecting a calculation method to estimate sediment and nutrient loads in streams: Application to the Beaurivage River (Québec, Canadá). Journal of hydrology, p. 1-16, 2006.

SILVA, L.; WILLIAMS, D.D. Buffer zone versus whole catchment approaches to studying land use impact on river water quality. Water Research, v. 35, p. 3462-3472, 2001.

TROIAN, A.; OLIVEIRA, S. V. de; DALCIN,D.; EICHLER,M. L. $O$ uso de agrotóxicos na produção de fumo: algumas percepções de agricultores da comunidade Cândido Brum, no Município de arvorezinha (RS). In: Sociedade Brasileira de Economia, Administração e Sociologia Rural, 2009.

YAMADA, T.; LOGSDON, S. D.; TOMER, M. D.; BURKART, M. R. Groundwater nitrate following installation of a vegetated riparian buffer. Science of the Total Environment, v. 385, p. 297-309, 2007.

\section{Influence Of Land Use On The Transport Of Annual Loads Of Polluants In An Agricultural Watershed}

\section{ABSTRACT}

Water quality can be affected by physical, climatic and anthropic factors and by land use and land cover in the watershed. This work aims to evaluate the influence of the use and occupation of land in the transport of annual loads of pollutants in a watershed. The study is applied to an agricultural watershed (Concórdia river watershed) located in Lontras - Santa Catarina. Water quality data were used, obtained from monthly samplings at six points spatially distributed along the main river and its tributaries. The pollutant loads were quantified based on flows simulated by a conceptual hydrological model. The analysis of land use and occupation in the basin was derived from a survey conducted in 2008. Land use and occupation were analyzed for a strip around the water courses, considered a riparian zone, and in the contributing watershed control sections. We conducted correlation analyses between uses and land occupation and pollutant loads. The natural condition, represented by the percentage of "native forest" land use influenced the reduction of pollutant loads. Land uses classified as "grazing", "planted forest" and "agricultural activities" were correlated with the increase of pollution loads in the stream basin. Land uses within the riparian zone were correlated with the quality of water similarly to those of the Concórdia basin.

Key-words: watershed management, water quality, diffuse pollution. 